(C) 1982. The Genetical Society of Great Britain

\title{
DETERMINATION OF THE ENVIRONMENTAL SENSITIVITY OF SELECTION LINES OF NICOTIANA RUSTICA BY THE SELECTION ENVIRONMENT
}

\author{
J. L. JINKS and H. S. POONI \\ Department of Genetics, University of Birmingham, B15 2TT, England
}

Received 30.vi.82

\section{SUMMARY}

Selection has been practised for high and low final height in a population of 81 highly inbred lines derived by single seed descent from a random sample of the $F_{2}$ of the cross of varieties 1 and 5 of Nicotiana rustica in the poorest, best and average of 15 environments. The properties of the resulting selections show that the high selection made in the best environment has a greater environmental sensitivity than that made in the poorest environment while the low selection made in the best environment has a lower environmental sensitivity than that made in the poorest environment. The selections made in the average environment have intermediate environmental sensitivities. These selections confirm the rules laid down by Jinks and Connolly (1975) relating the environmental sensitivities of selections to the selection environment.

\section{INTRODUCTION}

JiNKS and Connolly (1975) showed that both high and low selections for rate of growth in the basidiomycete, Schizophyllum commune, differed in their environmental sensitivities according to whether selection was based on assessments in a good or in a poor environment. They argued that this is inevitable where the environmental sensitivity of the character selected and its mean performance are, at least, in part under the control of different gene loci (Perkins and Jinks, 1968 and 1973; Caligari and Mather, 1975; Jinks, Jayasekara and Boughey, 1977). The greater the independence of the genetical control of the two aspects of the phenotype the greater the influence of the environment used for selection on the environmental sensitivity of the selections made in it.

The effect of the selection environment can be generalised as follows:

(a) Selection for high performance $(\mathrm{H})$ in an above average environment will lead to selections with above average environmental sensitivity (h).

(b) The same selection $(\mathrm{H})$ in a below average environment will lead to selections with below average environmental sensitivity (1).

(c) Selection for low performance (L) in an above average environment will lead to selections with below average environmental sensitivity (1).

(d) The same selection (L) in a below average environment will lead to selections with above average environmental sensitivity $(\mathrm{h})$. 
These expectations have a strong theoretical basis and unambiguous empirical support from the $S$. commune selection experiment (Jinks and Connolly, 1973, 1975; Connolly and Jinks, 1975). But while the results of selection experiments in mice (Bateman, 1971) and Tribolium (Orozco, 1976) are consistent with some aspects of these expectations no further independent supporting evidence has been reported. In this paper we therefore report pure breeding selections from the cross of varieties 1 and 5 of Nicotiana rustica which are in complete agreement with these expectations.

\section{Material}

The material is 81 of the 82 highly inbred lines derived from a random sample of the $\mathrm{F}_{2}$ of the cross of varieties 1 and 5 of $N$. rustica by single seed descent (Perkins and Jinks 1973). The data consist of final height recorded on 15 field assessments of these 81 lines in different seasons and locations and at different sowing dates and planting densities (for details see Pooni and Jinks, 1980 table 1). Of the 15 field trials the poorest in terms of plant growth and final size with an average plant height of $82.85 \mathrm{~cm}$ is a high density planting at the Avoncroft site in the exceptionally hot dry summer of 1976 . The best on the same criteria with an average plant height of $129.42 \mathrm{~cm}$ is a late sown trial at normal planting density on the University site in 1971. The mean performances and environmental sensitivities of the high $(\mathrm{H})$ and low (L) selections that would have been made on the basis of those two trials are given in table 1 . The mean performance is the average plant height achieved by a selection in all trials; environmental sensitivity is measured as the square root of the variance of plant height of a selection over all environments.

\section{TABLE 1}

The mean performances and environmental sensitivities of high and low selections for final height made in the poorest, best and in an average environment and on the basis of the mean performance in all environments

\begin{tabular}{lcccc} 
& \multicolumn{2}{c}{ High Selection } & \multicolumn{2}{c}{ Low Selection } \\
Selection Environment & $\begin{array}{c}\text { Mean } \\
\text { performance }\end{array}$ & $\begin{array}{c}\text { Environmental } \\
\text { sensitivity }\end{array}$ & $\begin{array}{c}\text { Mean } \\
\text { performance }\end{array}$ & $\begin{array}{c}\text { Environmental } \\
\text { sensitivity }\end{array}$ \\
& 123.76 & 14.59 & 94.62 & 12.14 \\
Poorest & 141.11 & 16.16 & 85.24 & 11.53 \\
Average & 131.33 & 20.44 & 91.63 & 8.36 \\
Best & 141.11 & 16.16 & 83.42 & 9.97 \\
Mean of all & & & &
\end{tabular}

For comparison the mean performances and environmental sensitivities of two controls are also given in table 1. One is the high and low selections that would have been made on the basis of the trial which was conducted in the average of the 15 environments where the average plant height was $112.68 \mathrm{~cm}$. The second is the high and low selections that would have been made on the basis of the average plant heights of the 81 lines over all 15 environments, that is, on their mean performances which averaged $112.45 \mathrm{~cm}$. 


\section{Results}

The mean performances and environmental sensitivities of the high and low selections as measured over all 15 environments show (table 1):

(a) The better the selection environment the higher the environmental sensitivity of the high selection and the lower the environmental sensitivity of the low selection. Hence, the high selection made in the poorest environment has below average environmental sensitivity while that made in the best environment has above average environmental sensitivity. For the low selections the relationship between the quality of the selection environment and the sensitivities of the resulting selections is the reverse of that for the high selections.

(b) Selections made in an average environment or on average performance in all environments have intermediate levels of environmental sensitivity.

(c) The mean performance of the high selection made in the average environment is higher than those of the high selections made in the two extreme environments. Similarly, the mean performance of the low selection made in the average environment is lower than those of the low selections made in the two extreme environments. The superiority of the selections made in the average environment is shared and only marginally improved upon by making the selections on the basis of average performance over all 15 environments.

\section{Conclusions}

For characters such as final height in the cross of varieties 1 and 5 of $N$. rustica where there are heritable differences in environmental sensitivity which are at least in part independent of those for mean performance (Perkins and Jinks, 1968 and 1973) the environment in which selections are made automatically determines the environmental sensitivities of the resulting selections. The relationship between the selection environment and the environmental sensitivity of the selections is predictable by the rules laid down by Jinks and Connolly (1975) and summarised in section 1.

For final height in the V1 $\times$ V5 cross the mean performance of the selections are also affected by the selection environment, the selections made in the average environment being the most successful over all environments (table 1). The explanation is simple. Most of the 15 environments, on the criteria used (section 2) are close to the average, 8 of them occupying the middle fifth of the range. For this reason the high and low selections made in the average environment are the highest and lowest in 9 and 5 of the environments, respectively. In contrast the high and low selections made in the extreme environments are, with one exception, the highest and lowest in the selection environment only, the exception being the high selection in the best environment which is also the highest in one other environment.

Finally, comparison of the mean performances and environmental sensitivities of the high and low selections (table 1) throws a new light on the widely reported "scalar relationship" generated by high performance being associated with high sensitivity (high variance) and low performance 
with low sensitivity (low variance). Between the high and low selections made in the poorest environment the relationship is hardly noticeable and indeed they do not differ significantly in their environmental sensitivities. This relationship is, however, most marked between the selections made in the best environment and to a lesser extent by those made in an average environment. The familiar scalar relationship is not, therefore, merely a statistical consequence of the differences in the means of high and low selections. It is rather a consequence of the relationships between the genetic systems controlling mean performance and environmental sensitivities and between the environments in which selection is practised and the environments in which the properties of the selections are observed.

The importance of taking into account the environments in which selections will be raised when choosing the environments in which the selections will be made has long been appreciated. Our observations show that the reasons for doing so are more profound than are generally recognised.

\section{REFERENCES}

BATEMAN, N. 1971. Selection of mice for growth on constant and on changing maize-milk diets. Anim. Prod., 13, 425-440.

CALIGARI, P. D. S., AND MATHER, K. 1975. Genotype-environment interaction. III. Interactions in Drosophila melogaster. Proc. $R$. Soc. Lond. B. 191, 387-411.

CONNOLLY, V., AND JINKS, J. L. 1975 The genetical architecture of general and specific environmental sensitivity. Heredity, 35, 249-259.

JINKS, J. L., AND CONNOLLY, V. 1973. Selection for specific and general response to environmental differences. Heredity, 30, 33-40.

JINKS, J. L., AND CONNOLLY, V. 1975. Determination of the environmental sensitivity of selection lines by the selection environment. Heredity, 34, 401-406.

JINKS, J. L., JAYASEKARA, N. E. M., AND BOUGHEY, H. 1977. Joint selection for both extremes of mean performance and sensitivity to a macroenvironmental variable. II. Single seed descent. Heredity, 39, 345-355.

OROZCO, F. 1976. A dynamic study of genotype-environment interaction with egg laying of Tribolium castaneum. Heredity, 37, 157-171.

PERKINS, J. M., AND JINKS, J. L. 1968. Environmental and genotype-environmental components of variability. III. Multiple lines and crosses. Heredity, 23, 339-356.

PERKINS, J. M., AND JINKS, J. L. 1973. The assessment and specificity of environmental and genotype-environmental components of variability. Heredity, 30, 111-126.

POONI, H. S., AND JINKS, J. L. 1980. Non-linear genotype x environment interaction. II. Statistical models and genetical control. Heredity, 45, 389-400. 